\title{
Transmission of Tuberculosis in Havana, Cuba: a Molecular Epidemiological Study by IS6110 Restriction Fragment Length Polymorphism Typing
}

\author{
R Diaz/+, RI Gomez, E Restrepo*, R Rumbaut**, J Sevy-Court**, JA Valdivia, \\ D van Soolingen***
}

\begin{abstract}
Laboratorio Nacional de Referencia en Tuberculose y Micobacteria, Instituto Pedro Kourí, Casilla Postal 601, Marianao 13, Havana, Cuba *Instituo Colombiano de Medicina Tropical, Medellín, Antioquia, Colombia **Centro Provincial de Epidemiología y Higiene, Havana, Cuba ***Diagnostic Laboratory of Infectious Diseases and Perinatal Screening, National Institute of Public Health and the Environment,
\end{abstract} 3720 BA, The Netherlands

\begin{abstract}
The combination of molecular and conventional epidemiological methods has improved the knowledge about the transmission of tuberculosis in urban populations. To examine transmission of tuberculosis in Havana, Cuba, with DNA fingerprinting, we studied 51 out of 92 Mycobacterium tuberculosis strains isolated from tuberculosis patients who resided in Havana and whose infection was cultureconfirmed in the period from September 1997 to March 1998. Isolates from 28 patients (55\%) had unique IS6110 restriction fragment length polymorphism (RFLP) patterns, while isolates from 23 others (45\%) had identical patterns and belonged to 7 clusters. Three clusters consisting of six, five and two cases were each related to small outbreaks that occurred in a closed setting. Three other clustered cases were linked to a large outbreak that occurred in another institution. Younger patients were more correlated to clustering than older ones. The finding that $45 \%$ of the isolates had clustered RFLP patterns suggests that recent transmission is a key factor in the tuberculosis cases in Havana. The IS6110 RFLP typing made it possible to define the occurrence of outbreaks in two closed institutions.
\end{abstract}

Key words: DNA fingerprinting - epidemiology - IS6110 RFLP - Mycobacterium tuberculosis - transmission Havana - Cuba

After some decades of decline, the incidence rates of tuberculosis in Cuba increased from 4.9 cases/100,000 people in 1991 to 14.8 cases/100,000 inhabitants in 1994 (Marrero \& Carrera 1996). This increase seems to have been precipitated by the economic recession and the deterioration of the National Tuberculosis Control Program, which occurred during this period (Diaz et al. 1998). Although the swift increase of the disease was reversed in 1995 and the rate decreased to 13.8 cases/ 100,000 inhabitants in 1996.

Until recently, it was thought that a large proportion of tuberculosis cases in low-incidence countries was due to reactivation of latent remote infections, and that recent transmissions had a mi-

E Restrepo was the recipient of a Masters Degree at the Institute Pedro Kourí.

${ }^{+}$Corresponding author. Fax: 537-246051. E-mail: Raul.Diaz@ipk.sld.cu

Received 16 August 1999

Accepted 9 February 2001 nor role (Styblo 1991, American Thoracic Society 1992). In the last few years, the use of restriction fragment length polymorphism (RFLP) typing with different molecular markers and conventional epidemiological methods has improved understanding of the transmission of tuberculosis (Alland et al. 1994, Small et al. 1994). Recent studies, performed in urban regions in some developed countries, which used DNA fingerprinting show that about $40 \%$ of the tuberculosis cases can be classified into clusters with epidemiological links. Such studies suggest that one-third of the total cases are probably due to recent exogenous transmission (Alland et al. 1994, Small et al. 1994, van Deutekom et al. 1997, Gutiérrez et al. 1998). In a previous study, we report the large percentage (48\%) of clustered strains in Cuba, outside Havana, indicating that recently transmitted tuberculosis has an important role in this country (Diaz et al. 1998).

Havana, with two million inhabitants, representing $20 \%$ of the Cuban population, yearly reports one-third of all tuberculosis cases in Cuba. The incidence of tuberculosis in this region increased from 6.7 cases/100,000 inhabitants in 1991 to 20.1 cases $/ 100,000$ inhabitants in 1996 . The in- 
cidence decreased to 16.8 in 1997 , which was still much higher than the national average (Departamento de Epidemiología y Estadísticas 1997).

We applied IS6110 DNA fingerprinting to Mycobacterium tuberculosis strains isolated in Havana from September 1997 to March 1998 to detect active tuberculosis transmission and to estimate the incidence of tuberculosis that results from recent transmission of the disease. We also analyzed some outbreaks that occurred in closed institutions.

\section{MATERIALS AND METHODS}

Patient population and data collection - Between 20 September 1997 and 10 March 1998, a total of 92 patients with culture-positive tuberculosis were registered at the Statistics and Epidemiology Department of the Provincial Centre of Epidemiology and Hygiene, Havana. The majority of the patients $(92.4 \%)$ concerned new cases and seven of them had been previously treated with antituberculous drugs. All patients successfully completed their treatment. Demographic and clinical data were collected for all patients: age, sex, geographical origin, HIV serological status, date of diagnosis, previous treatment and contacts with people with tuberculosis. The contact-tracing results from a standardised questionnaire were also included. A further epidemiological investigation was performed for patients whose isolates had identical fingerprints and/or who were living in two closed institutions, referred to here as Institution A and Institution B. Ten patients were eliminated from the study due to incomplete data. Seven other patients were not included because they were temporary residents in Havana. Cultures for DNA fingerprinting were available for 56 of the 75 Havanan patients with complete data $(75 \%)$ and five isolates were excluded because of suspicion of laboratory cross-contamination. Therefore, isolates from 51 patients $(55 \%$ of the total cases with cultures) were subjected to IS6110 RFLP analysis.

Mycobacterial isolates - M. tuberculosis strains analyzed in this study were isolated in various health centres of Havana and sent to the Provincial Reference Laboratory of Tuberculosis at the Provincial Centre of Epidemiology and Hygiene. All isolates were identified as M. tuberculosis by this laboratory and submitted to the National Reference Laboratory on Tuberculosis and Mycobacteria, Institute Pedro Kourí, for further analysis.

RFLP analysis - IS6110 DNA fingerprinting of $M$. tuberculosis strains was performed as described by van Embden et al. (1993). RFLP patterns of the isolates were compared by visual examination. Patients were assigned to clusters if their isolates had identical IS6110 DNA fingerprints.
The IS6110 RFLP patterns of the study isolates were also compared to a collection of $284 \mathrm{M}$. tuberculosis fingerprints from strains isolated from various areas of Cuba between 1993 and 1997.

Statistical analysis - The chi-square test with Yates correction or Fisher's exact test (when expected values were less than 5) were used to evaluate the association of categorical variables. Values of $P<0.05$ were considered indicative of statistical significance.

\section{RESULTS}

IS6110 RFLP clustering - The copy number of IS 6110 of the Havanan strains ranged from 6 to 20 with an average of ten copies $( \pm 4)$. This large number of copies of the Cuban strains is described by Diaz et al. (1998). No strain had less than six copies of the repetitive element, and it enabled us to distinguish the totality of the isolates without using additional markers.

Among the 51 isolates analyzed, 35 different patterns were observed. Seven of these were shared by two or more patients' isolates and were detected in 23 strains (clustered isolates). The clustered isolates comprised $45 \%$ of the total strains, and they formed seven clusters consisting of two to six cases each (Table). The remaining 28 patterns were found only once. Representative IS6110 DNA fingerprints are shown in the Figure.

Correlation by gender and age - Although cases among male patients were more often clustered $(48 \%)$ than cases among female patients $(25 \%)$, this was not significant $(P>0.05)$. Younger age $(0-44$ years) was strongly associated with clustering (78\%). Patients within this age group belonged to a cluster more frequently than older patients $(P<0.05)$.

HIV status and clustering correlation - Of the 51 patients studied, only $3(6 \%)$ were HIV seropositive. However, the isolates from all three had DNA fingerprints identical to those of HIV-negative patients in either cluster 3 or cluster 7 (Table).

Epidemiological investigation of the RFLP clusters - An additional investigation for clustered patients was done to collect more epidemiological information.

Cluster 1 - This cluster consisted of two cases. Patients 1 and 2 lived in separate areas, and no apparent connection was detected.

Cluster 2 - Patients 3 and 5 were associated with a large outbreak that occurred in a hospital for mentally handicapped patients (Institution B), as reported by Gómez et al. (1997). We found a new case (patient 4), a health-care worker at the same hospital, who was working in a unit involved in the microepidemic during that period.

Clusters 3, 4 and 5- Thirteen cases (those of patients 6-18) made up these clusters, represent- 
TABLE

Main characteristics of tuberculosis cases from Havana involved in this study

\begin{tabular}{|c|c|c|c|c|c|}
\hline Patient & Sex & Age & Geographic origin & Date of diagnosis & RFLP pattern $^{a}$ \\
\hline 1 & M & 51 & Guanabacoa & $97 / 10 / 30$ & 1 \\
\hline 2 & M & 70 & Playa & $98 / 01 / 16$ & 1 \\
\hline 3 & M & 53 & Institution B & $97 / 11 / 28$ & 2 \\
\hline 4 & $\mathrm{~F}$ & 33 & Institution B & $98 / 01 / 07$ & 2 \\
\hline 5 & M & 38 & Institution B & $98 / 03 / 10$ & 2 \\
\hline 6 & M & 34 & Centro Habana $^{b}$ & $97 / 10 / 03$ & 3 \\
\hline 7 & M & 36 & Institution A & $98 / 01 / 16$ & 3 \\
\hline 8 & M & 39 & Institution A & $97 / 10 / 08$ & 3 \\
\hline 9 & M & 40 & Institution A & $98 / 02 / 18$ & 3 \\
\hline 10 & M & 23 & Institution A & $98 / 01 / 15$ & 3 \\
\hline 11 & M & 34 & Institution A & $97 / 11 / 28$ & 3 \\
\hline 12 & M & 24 & Institution A & $97 / 09 / 19$ & 4 \\
\hline 13 & M & 24 & Institution A & $97 / 10 / 17$ & 4 \\
\hline 14 & M & 19 & Cerro & $97 / 09 / 10$ & 5 \\
\hline 15 & M & 59 & Institution A & $97 / 12 / 10$ & 5 \\
\hline 16 & M & 35 & Arroyo Naranjo $^{b}$ & $97 / 12 / 04$ & 5 \\
\hline 17 & M & 24 & Institution A & $98 / 02 / 20$ & 5 \\
\hline 18 & $\mathrm{~F}$ & 41 & Centro Habana & $98 / 03 / 19$ & 5 \\
\hline 19 & M & 55 & Centro Habana & $97 / 12 / 10$ & 6 \\
\hline 20 & M & 44 & Centro Habana & $97 / 11 / 15$ & 6 \\
\hline 21 & M & 27 & Institution $\mathrm{A}^{c}$ & $97 / 12 / 12$ & 7 \\
\hline 22 & M & 42 & Centro Habana $^{c}$ & $98 / 01 / 16$ & 7 \\
\hline 23 & M & 37 & San M del Padrón & $98 / 01 / 08$ & 7 \\
\hline 24 & M & 73 & Diez de Octubre & $97 / 10 / 03$ & Unique \\
\hline 25 & M & 46 & Playa & $97 / 11 / 13$ & Unique \\
\hline 26 & M & 42 & Marianao & $97 / 11 / 14$ & Unique \\
\hline 27 & $\mathrm{~F}$ & 39 & Arroyo Naranjo & $97 / 09 / 23$ & Unique \\
\hline 28 & M & 37 & Habana Vieja & $97 / 10 / 21$ & Unique \\
\hline 29 & M & 23 & Institution A & $97 / 10 / 08$ & Unique \\
\hline 30 & M & 40 & Playa & $97 / 11 / 26$ & Unique \\
\hline 31 & M & 44 & Guanabacoa & $97 / 12 / 02$ & Unique \\
\hline 32 & M & 53 & Guanabacoa & $97 / 10 / 28$ & Unique \\
\hline 33 & M & 56 & San M del Padrón & $97 / 11 / 11$ & Unique \\
\hline 34 & M & 71 & Habana del Este & $97 / 09 / 01$ & Unique \\
\hline 35 & $\mathrm{~F}$ & 29 & San M del Padrón & $97 / 10 / 14$ & Unique \\
\hline 36 & M & 50 & Institution A & $97 / 11 / 08$ & Unique \\
\hline 37 & $\mathrm{~F}$ & 49 & Arroyo Naranjo & $97 / 09 / 25$ & Unique \\
\hline 38 & M & 77 & Habana del Este & $97 / 12 / 17$ & Unique \\
\hline 39 & M & 74 & Guanabacoa & $98 / 01 / 07$ & Unique \\
\hline 40 & M & 55 & Guanabacoa & $98 / 01 / 27$ & Unique \\
\hline 41 & $\mathrm{~F}$ & 63 & San M del Padrón & $97 / 12 / 19$ & Unique \\
\hline 42 & M & 29 & Institution A & $98 / 03 / 20$ & Unique \\
\hline 43 & M & 73 & Cotorro & $98 / 03 / 15$ & Unique \\
\hline 44 & M & 55 & Arroyo Naranjo & $98 / 02 / 11$ & Unique \\
\hline 45 & M & 59 & Centro Habana & $98 / 03 / 19$ & Unique \\
\hline 46 & M & 43 & Habana Vieja & $97 / 12 / 10$ & Unique \\
\hline 47 & M & 63 & Habana Vieja & $97 / 12 / 15$ & Unique \\
\hline 48 & $\mathrm{~F}$ & 27 & Habana del Este & $98 / 03 / 15$ & Unique \\
\hline 49 & M & 32 & Diez de Octubre & $98 / 03 / 10$ & Unique \\
\hline 50 & M & 73 & Cerro & $98 / 02 / 26$ & Unique \\
\hline 51 & $\mathrm{~F}$ & 25 & Marianao & $98 / 02 / 24$ & Unique \\
\hline
\end{tabular}

$a$ : DNA fingerprint of each patient. Numbers represent clusters; $b$ : patient who formerly resided in the Institution A; $c$ : patient who formerly resided in Villa Clara province. 

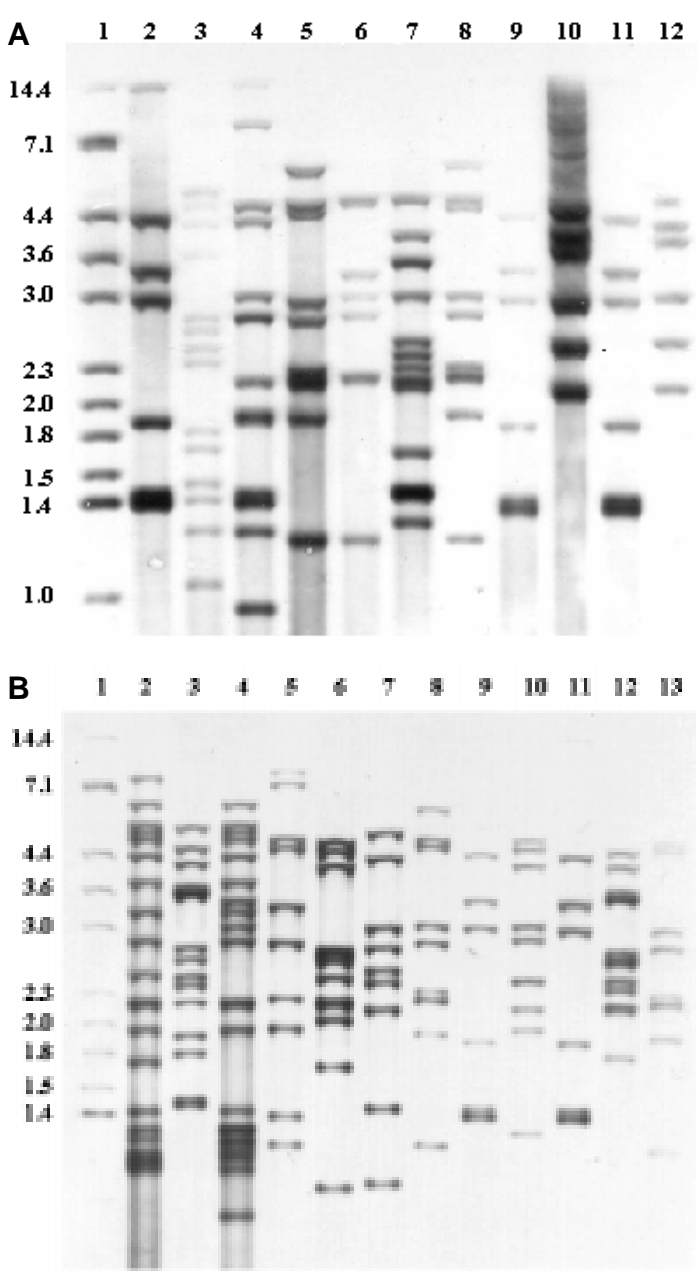

IS6110 DNA fingerprinting of 23 Mycobacterium tuberculosis strains isolated from various areas of Havana. A: lane 1 represents $M$. tuberculosis reference strain Mt 14323 in both panels. Lanes 2-12, patients 6 (cluster 3), 24, 26, 14 (cluster 5), 32, 34, 15 (cluster 5), 7 (cluster 3), 12 (cluster 4), 8 (cluster 3 ) and 36; B: lanes 2-13, patients 38, 39, 23 (cluster 7), 40, 42, 43, (cluster 5), 10 (cluster 3), 44, 11 (cluster 3), 45 and 18 (cluster 5). Numbers on the left indicate the sizes of standard DNA fragments in kilobase pairs $(\mathrm{kb})$.

ing $56 \%$ of the clustered cases. Ten were associated with an outbreak in another closed setting (Institution A).

Initially, a routine investigation had established that 15 tuberculosis patients in this study were living or had lived in Institution A. It seemed that all cases were somehow related to a microepidemic event in unit 3 of this institution. However, the IS6110 RFLP results defined seven distinct patterns in this set of strains.

The first pattern of seven bands was observed in six cases (cluster 3 ). Five of the six patients, including the two HIV-positive patients 9 and 10, lived in the same building (unit 3) for some months and these patients frequently visited common areas where some contact may have occurred. The other patient (no. 6), had resided in this setting three years earlier and no epidemiological link could be found.

Two isolates with the second pattern (12 IS6110 copies) pertained to cluster 4. Patients 12 and 13 lived in the same room of unit 1 for some months and then moved to unit 3 . They stayed there a very short time before diagnosis.

Five other isolates had a RFLP pattern of nine bands and were located in cluster 5. Patients 15 and 17 were living in the same closed institution, but they could not be connected with the other clustered patients. Patient 18, who had lived in Institution A a few years previously, was also included in this group, but we could not find any relation. Patient 18 was very controversial because this patient lived in a distant municipality, and no relation could be detected except that patients 15 and $18 \mathrm{had}$ once lived in the same neighbourhood. The fifth case in this cluster was that of patient 14, but no link could be found. The remaining four patterns were observed in patient 21 (cluster 7) and patients 29, 35 and 41 (non-clustered patients).

Cluster 6 - This cluster consisted of patients 19 and 20. They lived in the same neighbourhood, and they participated in some social activities.

Cluster 7-Patients 21 and 22, who had formerly resided in the province of Villa Clara showed a peculiar fingerprint, which had previously been found in a large set of strains from a closed setting in the community of this region and which was considered similar to the Beijing genotype family (van Soolingen et al. 1995, Diaz et al. 1998). Patient 23 showed the same fingerprint, but no information connecting them could be obtained.

Comparison of Havanan IS6110 RFLP patterns with a national fingerprint collection - We compared the 51 DNA fingerprints of the study isolates with those archived in a national collection at the NRLTBM. Thirteen Havanan strains shared three patterns with other Cuban strains. A DNA fingerprint of nine bands (cluster 2), found here in three cases, had previously been observed in a large set of isolates related to an Institution B outbreak (Gómez et al. 1997). It matched fingerprints of four strains isolated in the period 1994-1995 in three provinces: Holguin, La Habana and Las Tunas. No link could be found between these patients and the microepidemic patients. The second RFLP pattern of seven IS6110 copies, which were representative of cluster 3 (Institution A), was also found in seven strains of the national collection. Two patients of this group were diagnosed in Havana in the period 1994-1995. Another patient was also diagnosed in 1994 in a setting similar to that of Institution A. We 
found that the first of these two patients had lived with people of Institution A for some time. No other epidemiological link with Havanan clustered patients could be found. The remaining IS6110 DNA fingerprint was shared by four isolates of our study (cluster 5) and three strains isolated in the period 1994-1995 in Havana and La Habana provinces, respectively. No connection could be found among these patients.

\section{DISCUSSION}

We used IS6110 RFLP typing and conventional epidemiologic methods to investigate active tuberculosis transmission and its contribution to the increase of this disease in Havana in recent time.

Of the 51 isolates in this study, no strain showed fewer than six copies of IS6110, confirming the large percentage of Cuban isolates having more than five copies, as previously described (Diaz et al. 1995, 1998, Gómez et al. 1997). At present, 359 Cuban strains have been typed by IS6110 DNA fingerprinting, and only 15 isolates $(4.1 \%)$ showed less than six copies of this element. Moreover, the analysis of the IS6110 copy number in Havanan isolates reinforces this observation: we have found only a single low-copy strain $(0.8 \%)$ in 128 studied isolates. The high percentage of isolates containing high copy number of IS61160 in Havana is higher to that of other studies of American and European origin in such places as San Francisco (Small et al. 1994), New York (Alland et al. 1994), Paris (Gutiérrez et al. 1998) and Zaragoza (Samper et al. 1998) and very much higher than those of other reports from India, Ethiopia and Vietnam, where small numbers of IS6110 copies are more frequent (Das et al. 1993, Yuen et al. 1993, Hermans et al. 1995). Our findings reinforce the hypothesis of others (van Soolingen et al. 1995, Yang et al. 1995, Samper et al. 1998) that certain genotypes of $M$. tuberculosis are associated with particular geographic region. These data also corroborate the utility of IS6110 RFLP analysis in Cuba (and in Havana) for analysing the tuberculosis transmission in population-based studies or in particular settings.

We thought to find a large percentage of clustering in Havana to due the high density of the population $\left(3,021\right.$ people $/ \mathrm{km}^{2}$ ) (Anuario Demográfico de Cuba 1997), the crowding of some areas of the city and the deterioration of the provincial tuberculosis control program a few years ago leading to a $300 \%$ increase of the incidence in this region. Contrary to other countries, such as the United States, the Netherlands and France (Alland et al. 1994, Small et al. 1994, Borgdorff et al. 1998, Gutiérrez et al. 1998), there are very few imported tuberculosis cases, and they are not associated with clustering (data not shown).
The $45 \%$ of the Havanan isolates appearing in clusters suggest recent transmission. This is compatible with the results of another study (48\% clustering) with isolates from different provinces of Cuba (Diaz et al. 1998). However, we now typed three times less strains than in the former study. In previous population-based studies in urban areas such as San Francisco (Small et al. 1994), New York (Alland et al. 1994), Paris (Gutiérrez et al. 1998) and Amsterdam (van Deutekom et al. 1997), the percentage of clustered isolates ranged from $35 \%$ to $47 \%$. It could be that the recent exogenous transmission has been underestimated because only $55 \%$ of all cases with cultures in Havana during a 6-month period was analyzed. This could have been much higher, if the study period would have been more extended. For instance, in The Netherlands, a population-based molecular epidemiological study has been conducted from 1993 to date. It took two years before a plateau was reached in the clustering of cases (van Soolingen et al. 1999). Thereafter, the clustering percentage remained almost unchanged. On the other hand, it could also be that the recently transmitted tuberculosis in Havana has been overestimated because more than $50 \%$ of the clustered cases were directly related to two closed institutions. This great correlation in Cuba between clustering and closed settings was found earlier by Diaz et al. (1998), indicating that the total percentage of clustered isolates in the community has been affected by isolates directly related to institutional outbreaks.

In contrast to the former study (Diaz et al. 1998), the difference between female and male patients-clustering were not significant by the statistical test used (Fisher's exact test). This might be due to the very small number of female patients (there were 8 ) and due to the male/female ratio, which was $3: 1$. Younger patients were likely to belong to a cluster, as similarly found in previous studies (Small et al. 1994, Alland et al. 1994, Yang et al. 1995, Diaz et al. 1998), in whom the reactivation of latent lesions are less frequent than in older patients, particularly in countries with a small incidence of tuberculosis.

All three HIV-infected patients were living in Institution A, and they had clustered isolates. Several authors previously noted that people living in institutional settings and with HIV infection are more frequently associated with clustering because these conditions increase the likelihood of developing the disease (Valway et al. 1994, Frieden et al. 1996).

We found few connections between study patients and the national fingerprint database. Such comparisons could be very useful in the future to identify transmission routes in closed institutions or in the community. Recently, some authors have 
shown the utility of an international database located at the National Institute of Public Health and the Environment in Bilthoven, the Netherlands, to detect tuberculosis transmission across the borders (Kiers et al. 1997, Samper et al. 1997).

The fact that more than $50 \%$ of the clustered cases and $25 \%$ of the total cases were related to outbreaks occurring in an institution (Institution A) reflects the seriousness of the situation. Quickly dealing with the tuberculosis in Institution A might help to break the chains of transmission and limit the spread of M. tuberculosis throughout the community.

Finally, we can conclude that IS6110 DNA fingerprinting of Havanan isolates helped to find epidemiological links between tuberculosis cases, not previously obtained by conventional methods, and these results helped to estimate the magnitude of recent transmission of tuberculosis in this city.

In order to increase the knowledge of active transmission of the disease in Havana and to identify the risk factors associated with the transmission, a prospective study will be carried on in the near future.

\section{ACKNOWLEDGEMENTS}

To Gary Schoolnik of the Howard Hughes Medical Institute, Stanford University Medical School, for supplying the IS6110 primers. To Yenys Martínez and Miguel Echemendía for technical assistance and Roxana Chicoy and Otto Peláez for help with the data collection.

\section{REFERENCES}

Alland D, Kalkut GE, Moss AR, McAdam RA, Hahn JA, Bosworth W, Drucker E, Bloom BR 1994. Transmission of tuberculosis in New York City. An analysis by DNA fingerprinting and conventional epidemiologic methods. $N$ Engl J Med 330: 1710-1716.

American Thoracic Society 1992. Control of tuberculosis in the United States. Am Rev Respir Dis 146: 1623-1633.

Anuario Demográfico de Cuba 1997. Oficina Nacional de Estadísticas.

Borgdorff MW, Nagelkerke N, van Soolingen D, de Haas PEW, Veen J, van Embden JDA 1998. Analysis of tuberculosis transmission between nationalities in the Netherlands in the period 1993-1995 using DNA fingerprinting. Am J Epidemiol 147: 187-195.

Das S, Paramasivan CN, Lowrie B, Prabhakar R, Narayanan PR 1993. IS6110 restriction fragment length polymorphism typing of clinical isolates of Mycobacterium tuberculosis from patients with pulmonary tuberculosis in Madras, South India. Tuber Lung Dis 76: 550-554.

Departamento de Epidemiología y Estadísticas 1997. Centro Provincial de Higiene y EpidemiologíaCiudad de La Habana. Registro de tuberculosis.

Diaz R, Kremer K, de Haas PEW, Gómez RI, Marrero A, Valdivia JA, van Embden JDA, van Soolingen 1998. Molecular epidemiology of tuberculosis in
Cuba, outside of Havana, July 1994-June 1995; utility of Spoligotyping vs IS6110 restriction fragment length polymorphism. Int J Tuberc Lung Dis 2: 753750.

Diaz R, Montoro E, González R, Echemendía M, Valdivia JA 1995. Analysis of Mycobacterium tuberculosis strains isolated during an outbreak of $\mathrm{HIV}$-infected patients by DNA fingerprinting. Am J Trop Med Hyg 53: 155-156.

Frieden TR, Sherman LF, Maw KL, Fujiwara PI, Crawford JT, Nivin B, Sharp V, Hewlett D, Brudney K, Alland D, Kreiswirth BN 1996. A multi-institutional outbreak of highly drug-resistant tuberculosis. Epidemiology and clinical outcomes. JAMA 276: 1229-1235.

Gómez RI, Diaz R, Cabanas M, Valdivia JA 1997. Patrones genéticos de Mycobacterium tuberculosis aislados en un hospital psiquiátrico. Avances en Biotecnología Moderna IV: D38.

Gutiérrez MC, Vincent V, Aubert D, Bizet J, Gaillot O, Lebrun L, Le Pendeven C, Le Pennec MP, Mathieu D, Offredo O, Pangon B, Pierre-Audigier C 1998. Molecular fingerprinting of Mycobacterium tuberculosis and risk factors for tuberculosis transmission in Paris, France, and surrounding area. J Clin Microbiol 36: 486-492.

Hermans PWM, Massadi F, Guebrexabher H, van Soolingen D, de Haas PEW, Heersma H, de Neeling H, Ayoub A, Portaels F, Frommel D, Zribi M, van Embden 1995. Analysis of the population structure of Mycobacterium tuberculosis in Ethiopia, Tunisia, and the Netherlands: usefulness of DNA typing for global tuberculosis epidemiology. J Inf Dis 171: 1504-1513.

Kiers A, Drost AP, van Soolingen D, Veen J 1997. Use of DNA fingerprinting in international source case finding during a large outbreak of tuberculosis in the Netherlands. Int J Tuberc Lung Dis 1: 239-245.

Marrero A, Carrera L 1996. Tuberculosis in Cuba. Tuberc Lung Dis 77: 18.

Samper S, Iglesias MJ, Rabanaque MJ, Lezcano MA, Vitoria LA, Rubio MC, Gómez-Lus R, Gómez LI, Otal I, Martín C 1998. The molecular epidemiology of tuberculosis in Zaragoza, Spain: a retrospective epidemiology study in 1993. Int J Tuberc Lung Dis 2: 281-287.

Samper S, Martín C, Pinedo A, Rivero A, Blázquez J, Baquero F, van Soolingen D, van Embden JDA 1997. Transmission between HIV-infected patients of multidrug-resistant tuberculosis caused by $M y$ cobacterium bovis. AIDS 11: 1237-1242.

Small PM, Hopewell PC, Singh SP, Paz A, Parsonnet J, Ruston DC, Schecter Gf, Daley C, Schoolnik GK 1994. The epidemiology of tuberculosis in San Francisco. A population-based study using conventional and molecular methods. N Engl J Med 330: 17031709.

Styblo K 1991. Epidemiology of Tuberculosis, Royal Netherlands Tuberculosis Association, The Hague.

Valway SE, Greifinger RB, Papania M, Kilburn JO, Woodley C, di Ferdinando GT, Dooley SW 1994. Multi drug-resistant tuberculosis in the New York 
state prison system, 1990-1991. J Infect Dis 170: 151-156.

van Deutekom H, Gerritsen JJJ, van Soolingen D, van Ameijden EJC, van Embden JDA, Coutinho RA 1997. A molecular epidemiological approach to studying the transmission of tuberculosis in Amsterdam. Clin Infect Dis 25: 1071-1077.

van Embden JDA, Cave MD, Crawford JT, Dale JW, Eisenach KD, Gicquel B, Hermans PWM, Martin C, McAdam R, Shinnick TM, Small PM 1993. Strain identification of Mycobacterium tuberculosis by DNA fingerprinting: recommendations for a standardised methodology. J Clin Microbiol 31: 406-409.

van Soolingen D, Qian L, de Haas PEW, Douglas JT, Traore H, Portaels F, Zi Qing H, Enkhsaikan D, Nymadawa P, van Embden JDA 1995. Predomi- nance of a single genotype of Mycobacterium tuberculosis in countries of East Asia. J Clin Microbiol 33: 3234-3238.

van Soolingen D, Borgdorff MW, de Haas PEW, Kremer K, Veen J, Sebek MGG, Dessens M, van Embden JDA 1999. Molecular epidemiology of tuberculosis in The Netherlands: a nationwide study during 1993 trough 1997. J Infect Dis 180: 726-736.

Yang ZH, de Haas PEW, Wachmann CH, van Soolingen D, van Embden JDA, Andersen AB 1995. Molecular epidemiology of tuberculosis in Denmark in 1992. J Clin Microbiol 33: 2077-2081.

Yuen LK, Ross BC, Jackson KM, Dwyer B 1993. Characterization of Mycobacterium tuberculosis strains from Vietnamese patients by Southern blot hybridization. J Clin Microbiol 31: 1615-1618. 
444 Transmission of Tuberculosis in Havana, Cuba - R Diaz et al. 